Original Article

\title{
Evaluation of the Influence of Various Sprue Designs on Surface Porosity and Dimensional Accuracy of Base Metal Alloy Castings - An In Vitro Study
}

\author{
Nirupama R. ${ }^{1}$, Manoj Shetty ${ }^{2}$, Krishna Prasad D. ${ }^{3}$, Rakshith Hegde ${ }^{4}$ \\ ${ }^{1}$ Sr Lecturer, ${ }^{2,3,4}$ Professor, Department of Prosthodontics, A.B. Shetty M emorial Institute of Dental Sciences, Deralakatte, \\ Mangalore \\ *Corresponding Author : Nirupama R., Sr. Lecturer, Department of Prosthodontics, A.B. Shetty M emorial Institute of Dental Sciences, \\ Deralakatte, Mangalore. E-mail: niru_nidh@rediffmail.Com.
}

Received

: 05.04.2016

Review Completed : 14.10.2016

Accepted

: 02.11.2016

Keywords : Marginal discrepancy, Sprue designs, Base metal alloy castings, SEM analysis.

\begin{tabular}{|c|}
\hline Access this article online \\
\hline Quick Response Code \\
\hline
\end{tabular}

\begin{abstract}
Background and Objectives : Marginal fit of cast restoration is a major factor in long term survival of restoration. The sprue design is one of the variables that affect successful castings. Porosity can occur both on the surface and sub-surface of the casting. Base metal alloys have been used as an alternative to traditional high gold content alloys due to their superior mechanical properties.
\end{abstract}

The purpose of this study was to evaluate and compare the influence of various sprue designs on surface porosity and dimensional accuracy with conventional sprue design on five-unit singlepiece base metal alloy castings.

\begin{abstract}
Materials and Method: A metal die that stimulate a five unit Fixed partial denture was fabricated. Three different types of sprue designs was assigned to the pattern and casted. The marginal discrepancy was determined by measuring the space between the margin of the crown and the shoulder finish line of the abutment using Scanning electronic M icroscope(100X magnification). Surface porosity was evaluated using stereomicroscope (X10 Magnification).

Results : Best marginal fit based on the grand means and standard deviations was in the conventional design group followed by experimental $4 \mathrm{~mm}$ and $3 \mathrm{mmsprue}$ design. Significant differences was present in the $3 \mathrm{~mm}$ sprue when compared with $4 \mathrm{~mm}$ sprue $(<0.001)$ as well as the conventional design $(\varangle 0.001)$.
\end{abstract}

Interpretation and Conclusion: There was no surface porosity observed under stereomicroscope. When marginal discrepancy was compared with conventional design, $4 \mathrm{~mm}$ single sprue was more effective than the $3 \mathrm{~mm}$ single sprue.

\section{Introduction}

$M$ arginal fit of cast restoration is a major factor in long term survival of restoration. Marginal adaptation is one of the most significant factors influencing the clinical acceptability of the cast restoration. It is a critical parameter as the dissolution of the luting agent and the inherent roughness may result in secondary caries and plaque accumulation. Thus a good marginal fit is essential for maintaining gingival health and protecting the tooth from physical, chemical, thermal and bacterial injuries.

One of the critical factors associated with crown fabrication is the dimensional accuracy of a casting that must "fit" the prepared tooth. A multiunit long span fixed prosthesis presents an even greater challenge because inter- abutment distortions are a source of error that can compromise the optimal fit of retainer margins[1].

The sprue design is one of the variables that affect successful castings. Sprue design is a factor that controls the velocity and adequate supply of metal to the mold. Several studies in dental casting have demonstrated the importance of not only the size of the sprue but also its type, shape, location and direction[2].

Porosity has been a concern in dental casting techniques. Porosity can occur both on the surface and sub-surface of the casting. Ryge et al[2] characterized the porosities in dental castings into two distinct groups

1. Porosities caused by cooling and solidification as 
shrinkage, subsurface and microscopic porosities

2. Porosities caused by gas as gas pinhole porosity and gas inclusion

They recommended the use of a sprue diameter larger than the thickest cross-section of the casting to eliminate shrinkage porosity. Any surface irregularities effects the aesthetic appearance and difficult in oral hygiene maintenance. Internal porosities may increase the risk of mechanical failures.

Base metal alloys have been in use in Prosthodontics as an alternative to traditional high gold content alloys. These alloys attracted the attention of the dental professionals due to their superior mechanical properties. Base metal alloys have a reputation for being technique-sensitive. Their physical and chemical characteristics make them susceptible to cause changes in the casting environment [3].

Studies have shown that more complete base-metal castings were produced with the experimental sprue design[1].

\section{Materials}

Description of master die : A stainless steel analog that simulated a five unit fixed partial denture(FPD) preparation for 3 retainers and 2 pontics was fabricated (Figure: 1). Three metal dies were made and placed on a block with the help of retainer shaft in the position of canine, second premolar and second molar on one side of the arch. The die for the molars had the diameter of $9 \mathrm{~mm}$ at the finish line and height of $6 \mathrm{~mm}$. The die for the premolar had the diameter of $7 \mathrm{~mm}$ at the finish line and the height of $7 \mathrm{~mm}$. The die for the canine had the diameter of $6 \mathrm{~mm}$ and the height of $7 \mathrm{~mm}$. Each die had a uniform $1 \mathrm{~mm}$ shoulder finish line with $6^{\circ}$ convergence angle.

Custom made moulds were fabricated of stainless steel for each die in such a way that there was a uniform spacing of $0.5 \mathrm{~mm}$ between the die and the mould to obtain standardized waxpatterns.

Wax pattern fabrication : Wax patterns were made using type II inlay wax( crowax, Renfort ${ }^{\circledR}$, Germany) using a stainless steel split mold with $0.5 \mathrm{~mm}$ space for the patterns and a vent for the extra wax to flow out. Wax separating agent (Isolit ${ }^{\circledR}$, Degussa Germany) was used on the inner aspect of the mold and also on the die. After cooling the wax pattern was carefully separated from the mold. Excess wax was removed and the margins were burnished for close adaptation. Pontics pattern in relation to first premolar and first molar made from an index was attached to wax copings with help of connector to complete the five unit pattern(Figure:2). The wax pattern margins was accurately refined on the metal die using Stereomicroscope (under 10Xmagnification).

Three different types of sprue designs were assigned to the pattern(Figure:3).The point of attachment was flared to decrease porosity and increase mold filling. A $2.0 \mathrm{~mm}$ diameter wax sprue (Renfort ${ }^{\circledR}$, Germany) was attached at a $45^{\circ}$ angle to the occlusal surface of each wax pattern as primary sprue

Design 1 : A single curved sprue with $3.0 \mathrm{~mm}$ diameter attached to $2.0 \mathrm{~mm}$ primary sprue.

Design 2 : A single curved sprue with $4.0 \mathrm{~mm}$ diameter attached to $2.0 \mathrm{~mm}$ primary sprue.

Design 3 : A conventional design in which runner bar sprue of $3.0 \mathrm{~mm}$ diameter was attached to $2.0 \mathrm{~mm}$ primary sprue and three $3.0 \mathrm{~mm}$ diameter sprue was attached to runner bar(conventional method).

Total of ten 5-unit FPD wax patterns were made from each sprue design.

\section{Investing and casting:}

Wax patterns were immediately invested after marginal refinement to minimize distortion. The margins of all wax patterns were oriented in the standardized position of 30degrees inferior to the horizontal plane on the sprue former. A $6.0 \mathrm{~mm}$ distance was provided between the margin of the crown and the tip of the casting ring. A surface tension reducing agent (Waxit ${ }^{\circledR}$, Degudent Germany) was used to clean the wax patterns prior to investing. 
A notch was created on the external surface of each casting ring by placing a band of modelling wax on the crucible former before investing. This location was used to standardize ring orientation during the casting process. Patterns were vacuum-invested with a phosphate bonded investment material (Bellavest ${ }^{\circledR} \mathrm{SH}$ ) according to the manufacturer's recommendations for liquid/powder ratio in a number six casting ring lined with cellulose liner saturated with water. Investment was allowed to bench set for 45 minutes and the base formers were removed.

The ring was placed in a preheating furnace (Miditherm $200 \mathrm{mp} 220 \mathrm{v}$ preheating furnace $B E G 0^{\circ} \mathrm{USA}$ ) and heated to a temperature of $950^{\circ} \mathrm{C}$ at the rate of $7^{\circ} \mathrm{C} / \mathrm{min}$, and maintained at that temperature for 30 minutes. All casting procedures were carried out in Centrifugal- induction casting machine (Fornax $\mathrm{T}^{\mathrm{B} E G 0^{\circledR}}$ USA) with nickel chromium metal pellets (Wiron99 BEGO ${ }^{\circledR}$ Germany). All casting were cooled to room temperature before removal from casting ring. After bench cooling, the castings were divested manually, sandblasted lightly with $50 \mu \mathrm{m} \mathrm{Al}_{2} 03$ at $30 p s i$ pressure at a distance of approximately $5 \mathrm{~cm}$ to remove residual investment. The buttons of the casting were sectioned off, and all the sprues were removed with an abrasive disk, cleaned in ultrasonic solution for 15minutes, rinsed and dried (Figure:4).

\section{Methodology}

Method of measurement : A transfer block was made to hold the castings in the microscope(Figure:5). The location and quantity of surface porosity was evaluated using stereomicroscope (10XMagnification)

The marginal discrepancy was determined by measuring the space between the margin of the crown and the shoulder finish line of retainer using Scanning Electron M icroscope (SEM ) under 100X magnification(Figure:6).

Marginal discrepancy was noted at four reference points for each retainers(Figure:7), i.e.,

1. Mesiobuccal point

2. Distobuccal point

3. Mesiolingual point
4. Distolingualpoint

For each design

3 retainers in each pattern $x$

4 readings for each retainers $=12$ readings for each pattern. 10 patterns in each sprue designs $x$

12 readings for each pattern $=$ total of 120 readings for each design.

\section{Results}

The data was analyzed statistically using SPPSS 11.5 version and the results are presented in table I and II. ANOVA with post hoc test (Scheffe test) was applied for inter and intra group comparison

Comparison of marginal discrepancy among three designs was evaluated statistically with Anova test. The mean value of marginal discrepancy noted for experimental $3 \mathrm{~mm}$ sprue (Design I) was $164.5783 \mu \mathrm{m}$ and the calculated standard deviation was 80.46623 . The mean value of marginal discrepancy for experimental $4 \mathrm{~mm}$ sprue(Design II) was noted as $53.9433 \mu \mathrm{m}$ and standard deviation was 17.96851. For the conventional sprue design(Design III) the mean value of marginal discrepancy was $47.9717 \mu \mathrm{m}$ and the standard deviation was $11.8126 \mu \mathrm{m}$ (TABLEI).

The one way anova test shows that there is significantly higher discrepancy in the experimental $3 \mathrm{~mm}$ sprue followed by $4 \mathrm{~mm}$ and then the last by the conventional. Post hoc (Scheffe test) test was done for multiple comparison between each design.

Statistical comparison was evaluated between grand mean values of marginal discrepancy of all castings with three different sprue designs. Very high significant differences $(p \varangle 0.001)$ was seen for experimental $3 \mathrm{~mm}$ sprue when compared with experimental $4 \mathrm{~mm}$ sprue as well as the conventional design (TABLE II)

There was no statistically significant difference(.630) in the experimental $4 \mathrm{~mm}$ sprue and the conventional design.

\section{Discussion}

An important consideration in obtaining successful cast metal restorations is good marginal adaptation without 
any surface porosity. These important parameters have been evaluated with three different sprue designs on five unit metal framework. Fabrication of an one-piece fixed partial denture (FPD) has distinct advantages and disadvantages. The FPD provides an immediate evaluation of the fit and the maximum strength of the rigid connector[4]. Fusayama et al[5]compared the accuracy of four-unit single-piece castings of a dental copper alloy and the soldering of individual units. Their study documented that cast multiple units were more accurate than soldered castings.

Several studies in dental casting have demonstrated the importance of not only the size of the sprue but also its type, shape, location and direction[2].

According to Preston[6] Spruing has been described as an art that is not well understood or practiced. M any different patterns and sprue designs have been used in studies to measure marginal discrepancy and porosity. Base metal alloys have been used as an alternative to traditional high gold content alloys in Prosthodontics. The light weight and rigidity of this metal are particularly effective in long-span fixed prostheses.

In a study where an evaluation of non-precious alloys for use with porcelain veneers was conducted by M offaetal[6] revealed that the shear bond strength between porcelain and metal values are significantly higher than the control gold based alloy. The Vickers hardness values of the nonprecious alloys ranged from 270 to 310 and are similar to those for dental enamel ( 260 to 300 ). Since hardness has been used to indicate potential abrasion resistance and strength properties, these high values are desirable. The superior sag resistance of these alloys is another noteworthy property. It should allow the fabrication of longer-span bridges (fixed partial dentures) with decreased probability of distortion arising from the elevated porcelain firing temperatures.

Poor marginal adaptation is one of the reasons for the failure of crowns and fixed partial dentures. A multiunit FPD presents an even greater challenge because interabutment distortions are a source of error that can compromise the optimal fit of retainer margins. The reason for failure may be microleakage which may further lead to secondary caries and plaque accumulation potential of the fixed partial restorations increases leading to periodontal breakdown.

This study was designed to evaluate and compare the influence of various sprue designs on surface porosity and dimensional accuracy with conventional sprue design on five-unit single-piece base metal alloy castings.

A metal die that simulate a five unit FPD preparation of three crowns and two pontics was fabricated. Three different types of sprue designs was assigned to the pattern.

Total of 10 five unit FPD was made for each sprue design and casted. The marginal discrepancy was determined by measuring the space between the margin of the crown and the shoulder finish line of the abutment using SEM .

By using standardized metal dies of volumetric size similar to that of teeth, wax patterns were fabricated and casted to standardized size and shape, thus decreasing the variation within each group. The machined dies also enable the investigator to accurately control the variables of preparation dimensions, and the finish line dimensions. The metal dies were placed on the shaft at the position of canine, $2^{\text {nd }}$ premolar and $2^{\text {nd }}$ molar region on one side of the arch in order to simulate the arrangement of natural teeth in the oral cavity.

When observed under Stereomicroscope (10X) it was noted that there was no porosity seen on the surface of the castings in any of the three designs. It was considered that the castability was good due to flaring at the sprue attachment with the wax pattern.

The results of this study support the suggestion byCraig[7], who recommended a flaring at the sprue attachment to allow for an even flow of molten alloy into the mold to minimize turbulence which in turn decreases porosity. By flaring the sprue, the fluidity of the molten 
alloy was maintained and the possibility of premature solidification was decreased, resulting in more complete castings.

Complete casting without any visible porosity on the surface of the metal copings in this study confirmed the positive effect of sprue designs.

In this study, the marginal fit was evaluated by measuring the space between the margin of the crown and the shoulder finish line of retainer using SEM under 100X magnification. The finding of Jorgensen and Wakumoto[8] showed that a marginal discrepancy of $0.05 \mathrm{~mm}$. i.e., $50 \mu \mathrm{m}$ is the maximum that can be classified as clinically acceptable, this figure might be used as a starting point for evaluating the clinical acceptability of castings. Those which have marginal discrepancies above this figure could be considered unsatisfactory. Therefore, a value of 50um was selected as the maximam discrepancy that could be tolerated in the clinical restoration, and the results of the present study were reviewed with this concept in mind.

On evaluating the results for all the three designs it was seen that the marginal discrepancy for $3 \mathrm{~mm}$ single sprue design showed the maximum values ranging from $127 \mu \mathrm{m}$ to $266 \mu \mathrm{m}$ (Figure:8). The calculated mean values of retainers in relation to molar was $145.69 \mu \mathrm{m}$, for premolar was $163.16 \mu \mathrm{m}$ and for canine is $184.88 \mu \mathrm{m}$. The statistical analysis showed high significant changes $(p \varangle 0.001)$.The results of the marginal discrepancy obtained for the $4 \mathrm{~mm}$ single sprue design showed the values ranging from $40.80 \mu \mathrm{m}$ to $88.88 \mu \mathrm{m}$ (Figure:9). when the mean values were calculated for retainers in relation to molar was $61.47 \mu \mathrm{m}$, for premolar was $51.65 \mu \mathrm{m}$ and for canine is $48.70 \mu \mathrm{m}$, which was not statistically significant.For the conventional designs the marginal discrepancy values ranged from $25.3 \mu \mathrm{m}$ to $71.40 \mu \mathrm{m}$ (Figure: 10 ). The calculated mean values of retainers in relation to molar was $52.45 \mu \mathrm{m}$, for premolar was $48.66 \mu \mathrm{m}$ and for canine is $42.79 \mu \mathrm{m}$ (Graph-I)

The results of the marginal discrepancy obtained from all the three designs showed that there was minimal discrepancy for conventional design followed by $4 \mathrm{~mm}$ single sprue design and the maximum in $3 \mathrm{~mm}$ single sprue design. (Graph-II)

Multiple comparisons were analysed between the groups using Post hoc(scheffe test). The results showed there was very high significant differences $(p \varangle 0.001)$ was seen for experimental $3 \mathrm{~mm}$ sprue when compared with $4 \mathrm{~mm}$ single sprue design as well as the conventional design. There was no statistically significant difference seen between $4 \mathrm{~mm}$ single sprue design and the conventional design.

On the basis of the results of this study, it would be difficult to determine which of the design is superior over the range of castings obtained, especially as there is no widely accepted criterion for the satisfactory fit of cast restorations. However, the investigation has clearly substantiated the previously established conventional design concept will satisfy all the types of clinical castings encountered in a typical dental restorations. However the experimental $4 \mathrm{~mm}$ single sprue design also can be recommended as there was no statistical significant results seen when compared with conventional design.

Further studies utilizing these designs can be conducted to observe surface as well as internal porosity using Scanning Electron Microscope.

\begin{tabular}{|l|c|c|c|c|c|c|}
\hline M ARGINAL DISCREPANCY (IN M ICRONS) \\
\hline & N & Mean & $\begin{array}{c}\text { Std. } \\
\text { Deviation }\end{array}$ & $\begin{array}{c}\text { M ean } \\
\text { Square }\end{array}$ & $\mathrm{F}$ & Sig \\
\hline $\begin{array}{l}\text { EXPERIM ENTAL } \\
\text { 3mm SPRUE }\end{array}$ & 120 & 164.5783 & 80.46623 & 217457.6 & 223.774 & $<0.001$ \\
\hline $\begin{array}{l}\text { EXPERIM ENT } \\
\text { 4mm SPRUE }\end{array}$ & 120 & 53.9433 & 17.96851 & & & \\
\hline $\begin{array}{l}\text { CONVENTIONAL } \\
\text { DESIGN }\end{array}$ & & 120 & 47.9717 & 11.8126 & & \\
\hline Total & & 360 & 88.8311 & 71.98817 & & \\
\hline
\end{tabular}

Table 1:

\section{Conclusions}

Within the limitations of this study, the following conclusions are made based on the results:

1. There was no surface porosity observed under Stereomicroscope (10X).

2. When marginal discrepancy of the castings were 


\section{ny)HS}

Nitte University J ournal of Health Science

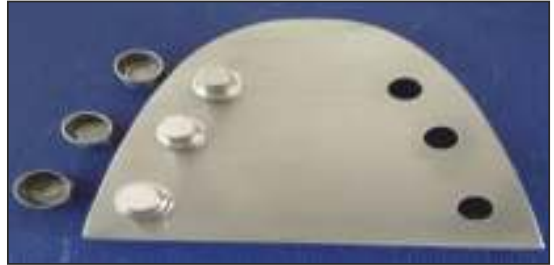

Figure 1

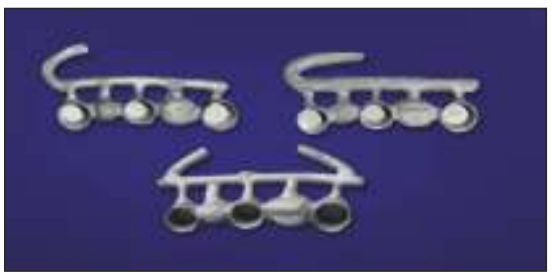

Figure 4

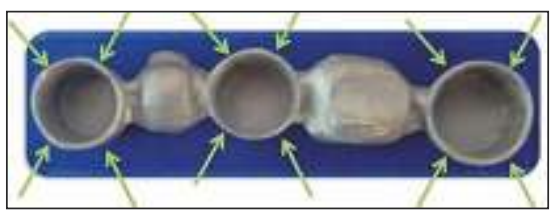

Figure 7

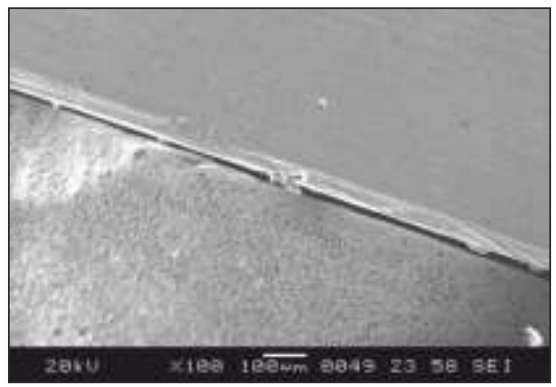

Figure 10

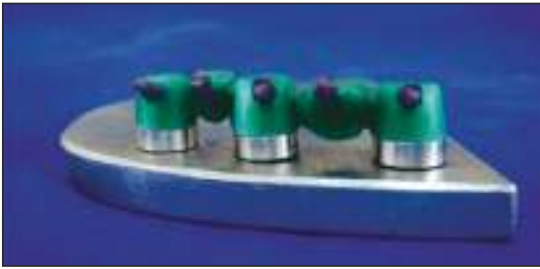

Figure 2

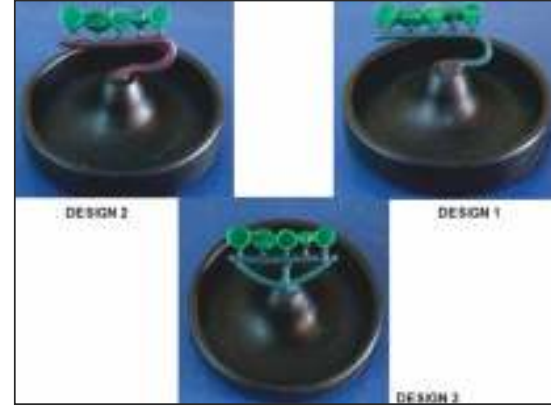

Figure 3

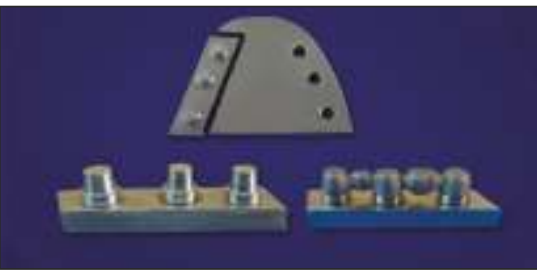

Figure 5

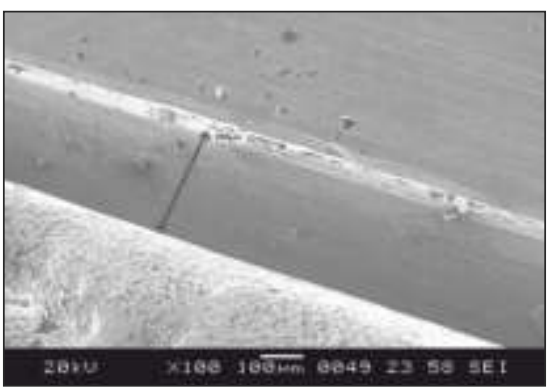

Figure 8

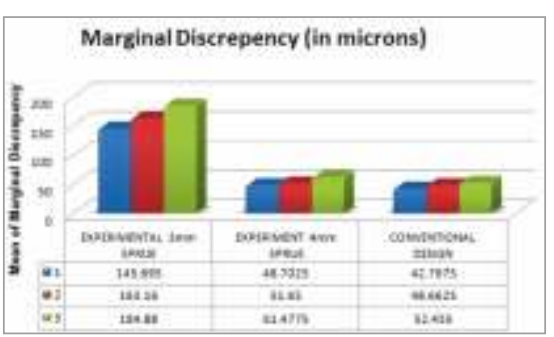

Graph 1

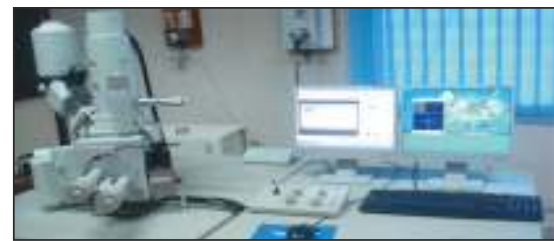

Figure 6

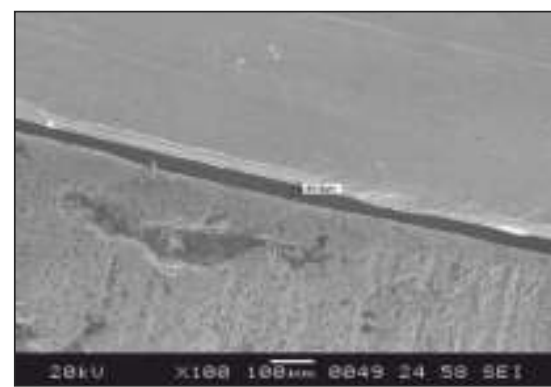

Figure 9

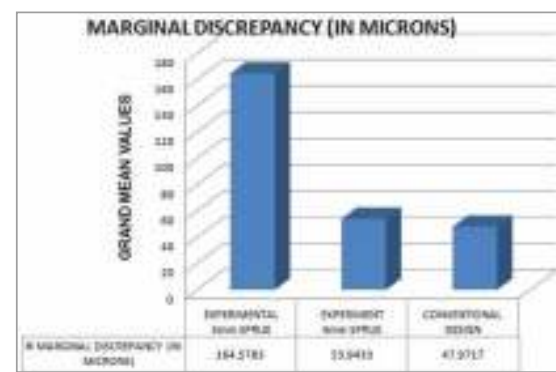

Graph 2

\begin{tabular}{|c|c|c|c|c|c|c|}
\hline (I) design & (J) design & $\begin{array}{c}\text { Mean } \\
\text { Diff. (I-J) }\end{array}$ & Std. Error & Sig & $\begin{array}{r}95 \% \mathrm{C} \\
\text { Int }\end{array}$ & $\begin{array}{l}\text { dence } \\
\text { al }\end{array}$ \\
\hline & & & & & Lower & Upper \\
\hline & & & & & Bound & Bound \\
\hline EXPERIM ENTAL & EXPERIM ENT & & & & & \\
\hline $3 \mathrm{~mm}$ SPRUE & $4 \mathrm{~mm}$ SPRUE & 110.62500 & 6.20807 & $\varangle .001$ & 95.3752 & 125.8948 \\
\hline & $\begin{array}{l}\text { CONVENTIONAL } \\
\text { DESIGN }\end{array}$ & 116.60667 & 6.6 .20807 & $\varangle .001$ & 101.3469 & 131.8664 \\
\hline $\begin{array}{l}\text { EXPERIM ENTAL } \\
4 \mathrm{~mm} \text { SPRUE } \\
\end{array}$ & $\begin{array}{l}\text { CONVENTIONAL } \\
\text { DESIGN }\end{array}$ & 5.97167 & 6.20807 & 630 & -9.22881 & 21.3314 \\
\hline
\end{tabular}

Table 2 
comparedbetween $3 \mathrm{~mm}$ single sprue design and conventional designs, the results seen was statistically significant.

3. When marginal discrepancy of the castings were compared between $4 \mathrm{~mm}$ single sprue design and

\section{References}

1. Thomas A. Wight, Richard J. Grisius, and Robert W. Gaugler, Ph.D. Evaluation of three variables affecting the casting of base metal alloys.JProstho Dent April 1980;43:415-418

2. Daniel Chan, Villa Guillory, Ronald Blackman, and Kwok-hung chung, The effects of sprue design on the roughness and porosity of titanium castings. J Prostho Dent October 1997;78:400-404

3. M.R.Rieger,.., R.A. Tanquist, and S. Vainer, The effect of new sprue design on the castability of a base metal alloy. J.Prostho Dent June 1986;55:686-690

4. Bruno E.Schiffleger, Gerald J. Ziebert, VirendraB.Dhuru, William A.brntleyKhosrowSingaroudi, Comparison ofaccuracy of multiunitone-piece castings. J Prostho Dent December 1985;54:770776

5. Takao Fusayama, SadaoWakumoto, Hiroyasu Hosoda, D.D.S., D.M.Sc. Accuracy of fixed partial dentures made by various soldering techniques and one-piece casting. J.Prostho Dent March-April 1964;14:334-342

6. Joseph P. Moffa, Armand A. Lugassy, Ph.D.,Albert D. Guckes, D.D.S., Lawrence Gettleman, D.M.D., M.S.D. An evaluation of nonprecious alloys for use with porcelain veneers. Part I. Physical properties J.Prostho Dent October 1973;30:424-431

7. Craig, R. 1985. Restorative Dental M aterials, Ed. 7., The C.V. M osby Co..

8. Clive B. G. Jenkins, and Ralph W. Phillips, An evaluation of five inlay investing techniques employed with different types of wax patterns. J.Prostho Dent February 1971;25:211-220. conventional designs, the results were not statistically significant.

4. Within the two experimental sprue designs $4 \mathrm{~mm}$ single sprue was more effective than the $3 \mathrm{~mm}$ single sprue. 